\title{
The First Genetic Map and Positions of Major Fruit Trait Loci of Bitter Melon (Momordica charantia)
}

\author{
Chittaranjan Kole ${ }^{1 *}$, Bode A. Olukolu ${ }^{2}$, Phullara Kole ${ }^{1}$, Virendra K. Rao ${ }^{3}$, Anju Bajpai ${ }^{4}$, S. Backiyarani ${ }^{5}$, Jogendra Singh ${ }^{6}$, R. Elanchezhian ${ }^{7}$ and \\ Albert G. Abbott ${ }^{1}$
}

\begin{abstract}
Albeit extensive cultivation of bitter melon both as vegetable and medicine in many countries of Asia, Africa, and South America, no serious efforts have been made for genetic and breeding studies on this 'orphan' crop. In contrast to popular cucurbits, it lacks a genetic linkage map as required for genomic depiction and precise breeding. We report here on the construction of the first genetic linkage map of bitter melon using a set of 146 F2 progenies derived from an inter-botanical variety cross between Taiwan White, Momordica charantia var. charantia, and CBM12, M. charantia var. muricata. This map consists of 108 AFLP markers and five qualitative trait loci dispersed over 11 linkage groups spanning a total distance of $3060.7 \mathrm{cM}$. The five qualitative traits mapped include fruit color, fruit luster, fruit surface structure, stigma color, and seed color; all of which exhibited monogenic segregation except seed color which showed digenic (9:7) mode of inheritance. Besides, twelve quantitative trait loci (QTL) controlling five polygenic fruit traits including length, diameter, weight, number, and yield were detected on five linkage groups that individually explained 11.1 to $39.7 \%$ of the corresponding total phenotypic variance. This map will be useful in marker-assisted breeding of these fruit traits and future mapping of genes/QTLs controlling phytomedicines content exhibiting contrasting variation between the parents.
\end{abstract}

\section{Introduction}

Bitter melon (Momordica charantia L.) also known as bitter gourd, balsam pear, bitter cucumber, and African cucumber is traditionally cultivated both for food vegetable and medicine in the tropical and subtropical areas of Asia, Amazon, East Africa, and the Caribbean. Albeit such importance, it still remains as an underutilized or orphan crop and no serious efforts have been made for elucidation of its genome or its genetic improvement.

M. charantia is a diploid species $(2 n=2 x=22)$ with a $1 C$ DNA content of $2.05 \mathrm{pg}$ and an estimated physical length of $2005 \mathrm{Mbp} / 1 \mathrm{C}$ [1]. The genome size is more than twice the genome size of other cucurbits (880 Mbp/1C for cucumis sativus, $440 \mathrm{Mbp} / 1 \mathrm{C}$ for Citrullus vulgaris, 929 $\mathrm{Mbp} / 1 \mathrm{C}$ for cucumis melo, $538 \mathrm{Mbp} / 1 \mathrm{C}$ cucurbita pepo) and 6.8 times the size of the Arabidopsis thaliana (0.3 pg and $295.6 \mathrm{Mbp} / 1 \mathrm{C}$ ) genome $[2,3]$. In contrast to popular cucurbits such as melon, watermelon and cucumber, there is no genetic linkage map for bitter melon and obviously no information on map positions of horticulturally desirable traits, particularly those related to fruit quality and yield.

Nonetheless, reports are available on the use of molecular markers including random amplified polymorphic DNA (RAPD), amplified fragment length polymorphism (AFLP), simple sequence repeat (SSR), and inter-simple sequence repeat (ISSR) for assessment of genetic diversity and population stratification [4-10]. Earlier observations evidenced for limited variation with regard to several fruit traits inter se the genotypes belonging to each of the two botanical varieties $M$. charantia var. charantia and M. charantia var. muricata but highly

*correspondence: ckole@clemson.edu

${ }^{1}$ Department of Genetics \& Biochemistry, 109 Jordan

Hall, Clemson University, Clemson, USA.

Full list of Author's information is available at the end of the article contrasting variation between them $[7,8,10]$. These two botanical varieties differ contrastingly with regard to shape, size [11], and many other qualitative and quantitative traits $[7,8,10]$. However, there is a need to map these traits for their precise breeding using molecular markers.

For this purpose, we used an $\mathrm{F}_{2}$ mapping population derived from a cross between two parents belonging to the two botanical varieties mentioned above and a set of AFLP markers to construct the first genetic linkage map for bitter melon. We localized the genetic loci controlling five qualitative and five quantitative traits, eight of which are economically important fruit traits.

\section{Materials and Methods Plant materials}

A set of $146 \mathrm{~F}_{2}$ individuals derived from an inter-botanical varietal cross were used for this study. The female parent, Taiwan White, belongs to the botanical variety $M$. charantia var. charantia. It produces white, glossy, and non-spiny fruits that have higher values for average length, maximum diameter (hereinafter mentioned as only diameter), and weight. The male parent, CBM12 (developed by us - US Patent Application No. 13/179952), belongs to the botanical variety M. charantia var. muricata. It bears green, dull, and spiny fruits with lower values for average length, diameter, and weight. Taiwan White bears less fruits but yields higher than CBM12. Two other contrasting qualitative traits include yellow stigma and black seed in Taiwan White vis-a-vis green stigma and creamy seed in CBM12 (C. Kole et al., unpublished results).

Twenty clones of a single $\mathrm{F}_{1}$ plant derived from the above cross were developed by vegetative propagation using stem cutting to ensure obtaining sufficient number of $F_{2}$ seeds. The female flowers of these plants were bagged before flowers opened and were hand-pollinated by rubbing matured anthers of the male flowers on receptive stigma of the female flowers early in the morning. The hybridized female 
flowers were kept bagged until formation of visually conspicuous green ovaries.

Plants were grown in 3-gallon pots (10.5" breadth and 9.5" height) filled with Fafard $3 \mathrm{~B}$ mix in greenhouses maintained at $80^{\circ} \mathrm{F}$ during the day, $65^{\circ} \mathrm{F}$ at night, and a relative humidity of $70-80 \%$. Plants were watered once a day. Peter Excel fertilizer solution of 15:5:15 of $\mathrm{N}, \mathrm{P}$ and $\mathrm{K}$, respectively (Scotts Corp.) was prepared by dissolving $1.36 \mathrm{~kg}$ of solid fertilizer in 3 gallons of water (ca. 120,000 ppm) and applied to the pots once in a week. Plant protection chemicals were applied when required to control diseases and insect-pests. Each plant was spaced at $40 " \times 24$ " on greenhouse benches (Ludy Greenhouse MFG Corp.).

\section{DNA isolation and molecular marker analysis}

Genomic DNA was extracted from fresh young leaves using the CTAB-PVP protocol described by Eldredge et al. [12]. AFLP marker analysis was performed essentially following Vos et al. [13]. In brief, an aliquot of $200 \mathrm{ng}$ of genomic DNA was digested with EcoRI and Msel, ligated to EcoRI and Msel adapters, and diluted 10-fold for pre-amplification. The pre-amplification reaction was set up using standard $\mathrm{E}$ and $\mathrm{M}$ primers corresponding to the EcoRI and Msel adapters, respectively, and containing one selective nucleotide ( $E+A$ and $\mathrm{M}+\mathrm{C}$ ) at the $3^{\prime}$ end. The pre-amplification reaction mixture was diluted 10 -fold and used for selective amplification using various combinations of $\mathrm{E}$ primers with 1 additional selective nucleotide and $\mathrm{M}$ primers with 2 additional selective nucleotides. The 256 primer combinations initially screened among the parents and 6 progenies include all combinations from EAA to ETT and MCAA to MCTT. Following screening, 23 primer combinations were chosen based on the polymorphism information content (PIC) and used for genotyping the mapping population.

Pre-amplification PCR conditions included 20 cycles of denaturing at $94^{\circ} \mathrm{C}$ for $30 \mathrm{~s}$, annealing at $56^{\circ} \mathrm{C}$ for $1 \mathrm{~min}$, and primer extension at $72^{\circ} \mathrm{C}$ for $1 \mathrm{~min}$, followed by a final extension at $72^{\circ} \mathrm{C}$ for $5 \mathrm{~min}$. Selective PCR conditions included 13 cycles of denaturing at $94^{\circ} \mathrm{C}$ for $30 \mathrm{~s}$, annealing at $65^{\circ} \mathrm{C}$ (decreasing by $0.7^{\circ} \mathrm{C}$ per cycle) for $1 \mathrm{~min}$, and primer extension at $72^{\circ} \mathrm{C}$ for $1 \mathrm{~min} ; 24$ cycles of denaturing at $94^{\circ} \mathrm{C}$ for $30 \mathrm{~s}$, annealing at $56^{\circ} \mathrm{C}$ for $30 \mathrm{~s}$, and primer extension at $72^{\circ} \mathrm{C}$ for $1 \mathrm{~min}$; and a final extension at $72^{\circ} \mathrm{C}$ for $5 \mathrm{~min}$. The $\mathrm{E}$ primers were end-radiolabeled with [ $\gamma$-33P]ATP (PerkinElmer) and T4 polynucleotide kinase (Promega). PCR products were separated on $6 \%$ denaturing polyacrylamide gels which were vacuum-dried, exposed to X-Omat blue XB-1 films (Kodak), and developed after 1-7 days.

\section{Recording of trait data}

Fully matured unripe fruits were picked from each $\mathrm{F}_{2}$ plant over the duration of fruit production. Some fruits were studied in situ and left to ripen for collection of seeds. Qualitative traits including fruit color (green/white), luster (dull/glossy), and surface structure (spiny/nonspiny) were recorded visually. Similarly, stigma color (yellow/green) and seed color (black/creamy) were visually scored. Length (cm), maximum diameter $(\mathrm{cm})$, and weight $(\mathrm{g})$ of each fruit was measured and averaged. The number of mature unripe; and ripe fruits were pooled together to record the total fruit number per plant. The total fruit yield was recorded using all matured fruits produced per plant just before they ripen since the fruits are commercially harvested as unripe matured green fruits for consumption.

\section{Linkage mapping and map construction}

Genotyped marker data were obtained from visual scoring of the banding patterns. The AFLP analysis produced predominantly dominant markers. Polymorphic and segregating bands generated from the same primer combination were named with an alphabetic suffix following the AFLP marker name. The linkage map was constructed based on 108 AFLP markers using Mapmaker/Exp v3.0 software [14] followed by generation of pictorial depiction of linkage groups using MapChart 2.2 [15]. Initial grouping of the linkage groups was performed at an LOD threshold of 3.25 and 0.40 recombination fractions. Each linkage group was framed using the three-point, compare, try, and finally ripple commands of the Mapmaker program. Some unlinked markers were added later using the try command. Segregation distortion of markers was determined by Chi-square goodness of fit analysis, while marker distances were calculated based on the Kosambi mapping function [16]. The Chi-square goodness of fit was employed to establish the mode of inheritance for the qualitative traits that were integrated into the genetic linkage map by linkage mapping as mentioned above.

\section{Mapping quantitative trait loci}

QTL analysis was performed based on simple interval mapping using PLABQTL software v1.2 [17]. The LOD curves were created by scanning at $5 \mathrm{cM}$ intervals, while a permutation test (1000 resamplings) was performed to determine the critical LOD score appropriate to empirically identify a putative QTL with a genome-wide error at a 0.05 confidence level [18]. A LOD threshold of 3.0 was used to declare putative QTLs since empirically computed LOD thresholds for the traits were slightly lower than 3.0. Different genetic models were compared based on Akaikes information criterion and Bayesian information criterion values [19] to determine the best regression fit. The phenotypic variance explained by each QTL $\left(R^{2}\right)$ was calculated as the square of the correlation coefficient from the final multiple regression model [20].

\section{Results}

\section{Genetic linkage map}

The genetic linkage map constructed includes 108 AFLP markers and 5 qualitative trait loci distributed over 11 linkage groups spanning a total of $3060.7 \mathrm{cM}$ with an average marker interval of $22.75 \mathrm{cM}$ (Table 1, Figure 1). Taking into account the large genome size of the M. charantia, which is more than twice that of other Cucurbits, the large map length of $M$. charantia is comparable to other cucurbits. Seven of the linkage groups contained 9 to 28 markers dispersed over 234.7 to $889.8 \mathrm{cM}$. The other four linkage groups had 2 to 5 
Kole et al. Journal of Plant Science \& Molecular Breeding 2012,

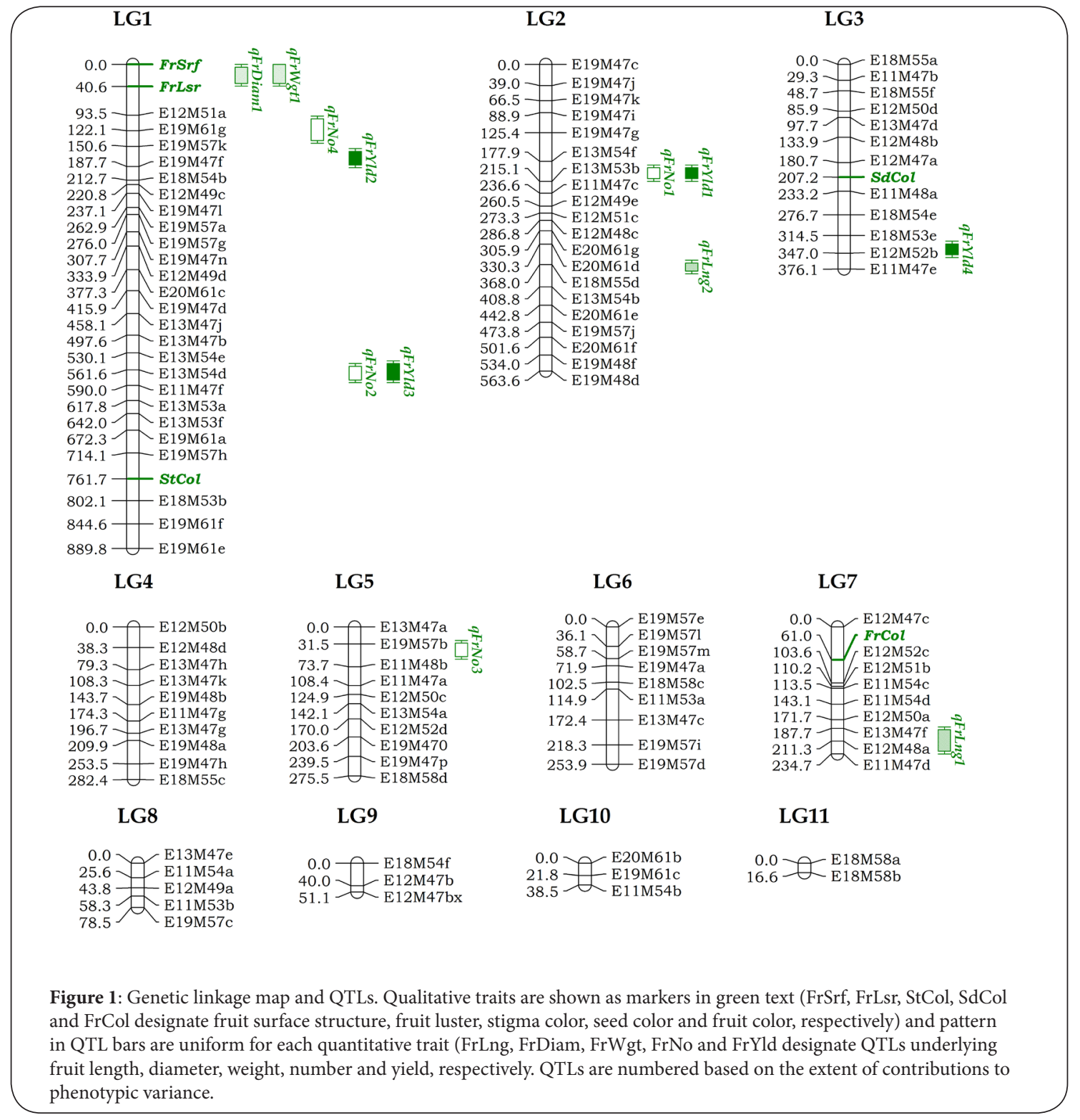

Table 1: Summary of genetic linkage map

\begin{tabular}{cccc}
\hline LG $^{*}$ & $\begin{array}{c}\text { Number } \\
\text { of loci }\end{array}$ & $\begin{array}{c}\text { Map } \\
\text { length, cM }\end{array}$ & $\begin{array}{c}\text { Average marker } \\
\text { interval, cM }\end{array}$ \\
\hline 1 & 28 & 889.8 & 31.78 \\
2 & 20 & 563.6 & 28.18 \\
3 & 13 & 376.1 & 28.93 \\
4 & 10 & 282.4 & 28.24 \\
5 & 10 & 275.5 & 27.55 \\
6 & 9 & 253.9 & 28.21 \\
7 & 10 & 234.7 & 23.47 \\
8 & 5 & 78.5 & 15.70 \\
9 & 3 & 51.1 & 17.03 \\
10 & 3 & 38.5 & 12.83 \\
11 & 2 & 16.6 & 8.30 \\
\hline Total & 113 & 3060.7 & 22.75 \\
\hline
\end{tabular}

${ }^{\star}$ LG designates linkage group markers dispersed over 16.6 to $78.5 \mathrm{cM}$. Segregation distortion was observed for 31 of the 108 markers at $P_{0.001}$.

\section{Inheritance of qualitative traits}

The parental varieties differ with regard to five qualitative reproductive traits including fruit color, fruit luster, fruit surface structure, stigma color, and seed color. Taiwan White bears white, glossy and non-spiny fruits; yellow stigma and black seeds, while CBM12 produces green, dull and spiny fruits; green stigma and creamy seeds. Their $F_{1}$ bore green, dull and spiny fruits; yellow stigma and black seeds. The $F_{2}$ plants exhibited monogenic (3:1) segregation for fruit color $\left(X^{2}=0.50\right)$, fruit luster $\left(x^{2}=0.76\right)$, fruit surface structure $\left(x^{2}=0.76\right)$, and stigma color $\left(x^{2}=0.63\right)$; but digenic mode of inheritance (9:7) for seed color $\left(x^{2}=0.46\right)$. 
Kole et al. Journal of Plant Science \& Molecular Breeding 2012,

http://www.hoajonline.com/journals/pdf/2050-2389-1-1.pdf

doi: $10.7243 / 2050-2389-1-1$

\section{Inheritance of quantitative traits}

The values for the mean, variance, standard deviation, coefficient of variation, and range for these traits recorded on the $F_{2}$ population are provided in Table 2. Although the distribution for some traits was skewed, the multiple regression method for QTL detection in PlabQTL is robust to handle a dataset with non-normal distribution. Pearson correlation analysis revealed significant correlation inter se the five fruit traits (Table 3). However, very high correlation coefficient value was observed between fruit yield and number (0.86) and between fruit weight and diameter (0.89).

\section{Map positions of qualitative and quantitative traits}

LG1 contained three qualitative traits; including fruit surface structure (FrSrf), luster (FrLsr), and stigma color; (StCol), the former two being closely linked (Figure 1). Stigma color was mapped between E19M57h and E18M53b at 47.6 and $40.4 \mathrm{cM}$ apart, respectively. Fruit color ( $\mathrm{FrCO}$ ) was mapped on LG7 and was flanked by E12M47c and E12M52c at distance of $61.0 \mathrm{cM}$ and $42.6 \mathrm{cM}$, respectively. Only one of the two genes (digenic mode of inheritance) controlling seed color ( $\mathrm{SdCol}$ ) was mapped on LG3 between E12M47a and E11M48a at 26.5 and $26.0 \mathrm{cM}$ apart, respectively.

A total of 12 quantitative trait loci (QTLs) were detected for the five quantitative fruit traits based on additive and dominance models (Table 4). Fruit length had two QTLs; one each on LG7 and LG2, contributing $13.4 \%$ of the phenotypic variance with a LOD value of 4.54. Fruit diameter and weight had one QTL each, both on LG1, explaining phenotypic variance of $12.9 \%$ and $11.1 \%$, respectively with LOD values of 4.34 and 3.71, respectively. Four QTLs, two on LG1 and one each on LG2 and LG5, were detected for fruit number that jointly contributed $39.7 \%$ of the phenotypic variance and had an LOD value of 16.05. Fruit yield had four QTLs, two on LG1 and one each on LG2 and LG3, contributing a total of $38.1 \%$ of phenotypic variance and an LOD value of 15.19 .

Individual LOD values of the 12 QTLs ranged from 3.02 to 8.12 and the contribution to the total phenotypic variance ranged between $4.42 \%$ and $15.32 \%$. QTL alleles for all of the traits were inherited from the female parent Taiwan White, except for four QTLs, one each for fruit length, fruit number, and two for fruit yield. Most of the QTLs evidenced for dominance effects except four QTLs, one each for fruit length, fruit diameter, fruit weight, and fruit number.

\section{Discussion}

The present study reports the first genetic linkage map for bitter melon. With the maximum marker interval of $61.0 \mathrm{cM}$ and an average marker interval of $27.1 \mathrm{cM}$, there is a need for extensive map saturation in order to facilitate detection of closely linked or functional markers for marker-assisted selection and map-based cloning of genes of interest. Moreover, we found some marker intervals with distance exceeding $50 \mathrm{cM}$, for example 52.9 and $57.6 \mathrm{cM}$ in LG1, $52.5 \mathrm{cM}$ in LG2, 57.5 cM in LG6, and 61.0 cM in LG7. These higher centiMorgan distances are the results of higher, but $<50.0 \%$, total recombination percentages due to higher expected double crosses in addition to the single cross-over events [21].
Table 2. Basic statistics for five quantitative fruit traits

\begin{tabular}{lllllll}
\hline Traits & Mean & $\begin{array}{l}\text { Vari- } \\
\text { ance }\end{array}$ & $\begin{array}{l}\text { Std. } \\
\text { dev }\end{array}$ & $\begin{array}{l}\text { Skew- } \\
\text { ness }\end{array}$ & $\begin{array}{l}\text { Kurto- } \\
\text { sis }\end{array}$ & Range \\
\hline Length $(\mathrm{cm})$ & 5.6 & 1.9 & 1.37 & 0.35 & 0.04 & $2.3-10.2$ \\
Diameter $(\mathrm{cm})$ & 3.5 & 0.35 & 0.60 & 0.04 & -0.07 & $1.9-5.0$ \\
weight $(\mathrm{g})$ & 20.8 & 106.8 & 10.33 & $0.63^{* *}$ & -0.21 & $3.0-48.0$ \\
Fruit No. & 13.3 & 87.8 & 9.37 & $0.98^{* *}$ & 0.26 & $1.0-43.0$ \\
Yield $(\mathrm{g})$ & 310.5 & 99212 & 314.98 & $2.00^{* *}$ & $5.57^{* *}$ & $3.0-1988$ \\
\hline
\end{tabular}

** denotes significance at P0.01 level

Table 3. Pearson correlation coefficients between five quantitative fruit traits.

\begin{tabular}{lllll}
\hline & Diameter & Weight & No. & Yield \\
\hline Length & $0.77^{* *}$ & $0.78^{* *}$ & $0.18^{*}$ & $0.42^{* *}$ \\
Diameter & & $0.89^{* *}$ & $0.24^{*}$ & $0.49^{* *}$ \\
Weight & & & $0.36^{* *}$ & $0.68^{* *}$ \\
No. & & & & $0.86^{* *}$ \\
\hline
\end{tabular}

${ }^{*}$ and ${ }^{* *}$ denote significance at P0.05 and P0.01 levels, respectively.
Table 4. QTLs detected using simple interval mapping.

\begin{tabular}{lclllll}
\hline Trait & LG & SI (cM) & LOD & R2 (\%) & A & D \\
\hline Fruit length & 2 & $365-380$ & 3.53 & 4.84 & - & 0.85 \\
\hline$R 2=13.4 \pm 5.3 \%$ & & & & & & \\
$L O D=4.54$ & 7 & $190-230$ & 3.02 & 10.21 & -0.47 & - \\
\hline Fruit diameter & & & & & & \\
$R^{2}=12.9 \pm 5.2 \%$ & 1 & $5-35$ & 4.34 & 12.87 & -0.60 & - \\
$L O D=4.34$ & & & & & & \\
\hline Fruit weight & & & & & & \\
$R^{2}=11.1 \pm 4.9 \%$ & 1 & $0-35$ & 3.73 & 11.11 & -0.56 & - \\
$L O D=3.71$ & & & & & & \\
\hline & 1 & $100-140$ & 6.84 & 4.75 & - & -0.86 \\
Fruit number & 1 & $555-580$ & 7.52 & 6.77 & 0.48 & - \\
$R^{2}=39.7 \pm 6.3 \%$ & 2 & $190-210$ & 6.99 & 7.51 & - & -1.39 \\
$L O D=16.05$ & 5 & $30-55$ & 6.47 & 6.44 & - & -0.84 \\
\hline & 1 & $160-185$ & 6.06 & 7.38 & - & -1.24 \\
Fruit yield & 1 & $550-580$ & 4.50 & 6.47 & - & 0.76 \\
$R^{2}=38.1 \pm 6.3 \%$ & 2 & $190-210$ & 8.12 & 15.32 & - & -1.99 \\
$L O D=15.19$ & 3 & $330-350$ & 3.32 & 4.42 & - & 0.87 \\
\hline
\end{tabular}

Note: LG, linkage group; A, additive QTL effect; D, dominance QTL effect; SI, 2-LOD support interval in the fit; R2, percentage of phenotypic variance explained by the QTLs. Only QTLs above empirical threshold of 3.0 are listed (LOD threshold computed by 1,000 permutations). The positive and negative effects indicate that the allele which increases the trait values is in the paternal and maternal parent, respectively. 
Kole et al. Journal of Plant Science \& Molecular Breeding 2012,

http://www.hoajonline.com/journals/pdf/2050-2389-1-1.pdf

doi: $10.7243 / 2050-2389-1-1$

Fruit (epicarp) color governs its marketability; however, preference of color varies over regions. For example, green fruits are in demand in Southern China whereas white fruits are preferred in Central China. Similarly, dark green to glossy green fruits are preferred in Northern India while white fruits are favored in Southern India [22]. We found green fruit color to be completely dominant over white color and fruit color mapped to a single qualitative locus for the single dominant gene (FrCol). Suribabu et al. [23] and Vahab [24] also reported white epicarp to be recessive to green. The detection of only one of the two seed color loci $(S d C o l)$ is due to the fact that the phenotypic ratio (i.e. 9:7) did not reflect the genotypic ratio (i.e. 9:3:3:1). This was further supported by simple interval mapping (results not included) based on the 9:7 phenotypic ratio, which indicated that one of the two genes explained $46.4 \pm 6.1 \%$ of the phenotypic variance $\left(R^{2}\right)$ with a LOD threshold of 19.64 and mapped to the same location as SdCol. The additive effect of this QTL was -1.85 , indicating the allele leading to black seeds is from the maternal parent (Taiwan White). Srivastava and Nath [25] also found dark brown seed coat color to be dominant over light brown seed (Ibs) coat color. Vahab [24] observed spiny (triangular tubercles) fruit to be dominant over smooth. We also found spiny fruit surface structure to be completely dominant over smooth and controlled by a single dominant gene FrSrf. We found fruit luster and stigma color to be monogenic and mapped the single dominant genes, FRLsr and StCol, respectively governing them. However, available literature does not reveal any reports on their genetic inheritance. It is also worthwhile to mention that no consumer preference is known for seed color.

Fruit yield and its component traits including length, diameter, weight, and number have been dealt as quantitative traits in a large number of biometrical works (see for review 22 and references therein). We also found them polygenic, exhibiting continuous variation in the $F_{2}$ mapping population. Based on QTL analysis of these quantitative traits, the effects indicated that most of the alleles increasing the trait value had originated from the female parent, Taiwan White, which has superiority over CBM12 with regard to all of the traits except fruit number. In fact, the fruit number QTL in LG1 (qFrNo2) with the highest LOD had effects contributed by CBM12. QTLs controlling fruit number and yield were overlapping at two chromosomal locations on LG1 ( $q$ FrNo2 and qFrYld3) and LG2 ( $q$ FrNo1 and qFrYld1). Besides two QTLs, one controlling fruit number and another controlling fruit yield, were in close proximity at the top end of LG1 (qFrNo4 and qFrYld2). Such linkage could be substantiated by their higher correlation coefficient value of 0.86 (Table 3). Similarly, high correlation (0.89) between fruit diameter and weight was reflected in the similarity of their genomic location of one QTL controlling each of them - qFrDiam1 and $q F r W g t 1$ in LG1. Understanding phenotypic components that are associated with fruit yield will be important towards breeding for yield. A study in melon [26] confirms that fruit number and yield do share overlapping genomic regions underlying the traits. In support to the overlapping QTLs between fruit weight and diameter in our study, Yuan et al. [27] also showed that fruit weight, length, and diameter do have overlapping QTLs. Albeit inferiority of CBM12, a selection from the wild botanical variety Momordica charantia var. muricata (US Provisional Patent Application Serial \# 61/364,938), to Taiwan White with regard to most of the fruit traits, it contributed favorable QTL alleles for fruit length, number, and yield. Contribution of superior alleles for yield by wild species as inferior parents has been well documented by Tanksley and McCouch [28] with examples from tomato and rice.

The limited number of QTLs detected and the low value of contribution to total phenotypic variance for at least three traits (fruit length, diameter, and weight) in this study are probably due to the low marker density, hence suggesting the need for marker saturation. Since association of the trait loci with adjacent linked markers depends on proximity, large gaps reduce the power to detect genomic regions underlying these traits. The magnitude of the percentage of contribution to phenotypic variance ( $R^{2}$ values) for individual QTLs nevertheless corroborates to similar studies in melon $[26,29,30]$ and cucumber $[27,31,32]$. Bitter melon contains a large number of bioactives known for their medicinal properties. The two parents of the present mapping population, Taiwan White and CBM12, have been found to differ with regard to at least three bioactives - an anticancer phytomedicine, cucurbitacin-B and two antidiabetic phytomedicines; charantin and plant insulin - through our preliminary studies $[7,8,9,10]$. Variation in contents of these and many other bioactives are currently being assessed in the $F_{2}$ population to detect the potential genomic positions underlying their contents using the present genetic map as the framework.

\section{Acknowledgements}

This work was supported by a USDA-NIFA Award 2009-3530105041 to the first author. Five authors (Fourth to Eighth) acknowledge the Indian Council of Agricultural Research (ICAR) for sponsoring their training at the Clemson University through the National Agricultural Innovation Project.

\section{Author information}

${ }^{2}$ Department of Plant Pathology, North Carolina

State University, Raleigh NC 27695, USA.

${ }^{3}$ G.B. Pant University of Agriculture \& Technology,

Ranichauri, Uttarakhand 249199, India.

${ }^{4}$ Central Institute for Subtropical Horticulture,

Lucknow, Uttar Pradesh 227107, India.

${ }^{5}$ National Research Center for Banana, Trichy, Tamil Nadu 620102, India.

${ }^{6}$ ICAR Research Complex for NEH, Imphal, Manipur 795004, India.

${ }^{7}$ ICAR Research Complex for Eastern Region, Patna, Bihar 800014, India.

\section{Competing interests}

The Author's declare that they have no competing interests.

\section{Article history}

Senior Editor: Yong Pyo Lim, Chungnam National University, Korea. Received: 07-Apr-2012 Accepted: 25-Apr-2012 Published: 27-Apr-2012 


\section{References}

1. Ingle J, Timmis JN, Sinclair J: The Relationship between Satellite Deoxyribonucleic Acid, Ribosomal Ribonucleic Acid Gene Redundancy, and Genome Size in Plants. Plant Physiol 1975; 55;(3.);496-501. | Article | Pubmed Abstract | Pubmed Fulltext

2. Bennett MD, Leitch IJ, Price HJ, Johnston JS: Comparisons with Caenorhabditis (approximately $100 \mathrm{Mb}$ ) and Drosophila (approximately $175 \mathrm{Mb}$ ) using flow cytometry show genome size in Arabidopsis to be approximately $157 \mathrm{Mb}$ and thus approximately 25\% larger than the Arabidopsis genome initiative estimate of approximately 125 Mb. Ann Bot 2003; 91;(5.);547-57. | Article | Pubmed

3. Schmuths $H$, Meister A, Horres R, Bachmann K: Genome size variation among accessions of Arabidopsis thaliana. Ann Bot 2004; 93;(3.);317-21. | Article | Pubmed

4. Dey SS, Singh AK, Chandel D, Behera TK: Genetic diversity of bitter gourd (Momordica charantia L.) genotypes revealed by RAPD markers and agronomic traits. Sci Hort 2006; 109; 21-28. | Article

5. Behera TK, Gaikward AB, Singh AK, Staub JE: Comparative analysis of genetic diversity in Indian bitter gourd (Momordica charantia L.) using RAPD and ISSR markers for developing crop improvement strategies. Sci Hort 2008; 115; 209-217.

6. Behera TK, Gaikward AB, Singh AK, Staub JE: Relative efficiency of DNA markers (RAPD, ISSR and AFLP) in detecting genetic diversity of bitter gourd (Momordica charantia L.). J Sci Food Agric 2008; 88;(4);733-737. | Article

7. Kole C, Olukolu BA, Kole P, Abbott AG: Characterization of a Momordica charantia germplasm with AFLP and SSR markers. In: Molecular Markers in Horticulture Symp, Oregon State Univ, Corvallis 2009.

8. Kole C, Olukolu BA, Kole P, Abbott AG: Towards molecular breeding of dual-purpose varieties in bitter melon (momordica charantia L.). In: 4th Int Cucurbit Symp, Changsha, Hunan, China. Sept 21-26, 2009. | Article

9. Kole C, Olukolu BA, Kole P, Abbott AG: Towards phytomedomics with bitter melon (Momordica charantia L.) as a model. In: Int Conf on the Status of Plant \& Animal Genome Research, San Diego, CA, and P164. Jan 9-13, 2010.

10. Kole C, Olukolu BA, Kole P, Abbott AG: Association mapping of fruit traits and phytomedicine contents in a structured population of bitter melon (Momordica charantia L.). In: Thies JA, Kousik S, Levi A (eds) Cucurbitaceae 2010 Proceedings. Amer Soc Hort Sci, Alexandria, VA, pp 42-45, 2010.

11. Chakravarty, H. L. Cucurbits of India and their role in the development of vegetable crops. In: Bates DM, Robison RW, Jeffrey C (eds) Biology and utilization of Cucurbitaceae, Cornell University Press, Ithaca, NY, 1990; pp 325-334.

12. Eldredge L, Ballard R, Baird WV, Abbott A et al. Application of RFLP analysis to genetic-linkage mapping in peaches. HortScience 1992; 27(2), 160-163. | Article

13. Vos $P$, Hogers $R$, Bleeker M, Reijans $M$, van de Lee $T$, Hornes $M$, et al.: AFLP: a new technique for DNA fingerprinting. Nucleic Acids Res 1995; 23;(21.);4407-14. | Article | Pubmed Abstract | Pubmed Fulltext

14. Lincoln SE, Daly M, Lander ES: Constructing genetic maps with MAPMAKER/EXP 3.0 Whitehead Institute Technical Report, Cambridge, MA, 1992.

15. Voorrips RE: MapChart: software for the graphical presentation of linkage maps and QTLs. J Hered 2002; 93;(1.);77-8. | Article | Pubmed

16. Kosambi DD: The estimation of map distance from recombination values. Ann Eugen 1944;12, 172-175. | Article

17. Utz HF, Melchinger, AE: PLABQTL: a program for composite interval mapping of QTL. JQTL 2(1), 1996. | Article

18. Churchill GA, Doerge RW: Empirical threshold values for quantita- tive trait mapping. Genetics 1994; 138;(3.);963-71. | Article | Pubmed Abstract $\mid$ Pubmed Fulltext

19. Hjorth JSU: Computer intensive statistical methods. Chapman and Hall, New York, 1994.

20. Utz HF, Melchinger AE: PLABQTL: a computer program to map QTL. Version 1.0. Univ of Hohenheim, 1995. | Article

21. Haldane JBS: The combination of linkage values and the calculation of distance between loci of linked factors. J Genet 1919;8: 299-309. | Article

22. Behera TK, Behera S, Bharathi, John KJ, et al. Bitter gourd: botany, horticulture, breeding. In: Janick J (ed) Horticultural Reviews, WileyBlackwell 2010; pp 101-141. | Article

23. Suribabu B, Reddy NE, Ramarao M: Inheritance of certain quantitative and qualitative characters in bitter gourd (Momordica charantia L.). South Indian Hort 34, 380-382, 1986.

24. Vahab MA: Homeostatic analysis of components of genetic variance and inheritance of fruit colour, fruit shape, and bitterness in bitter gourd (Momordica charantia L.). PhD Thesis, Kerala Agri Univ 1989; India.

25. Srivastava VK, Nath P: Inheritance of some qualitative characters in Momordica charantia L. Indian J Hort 29, 319-321, 1972. | Article

26. Zalapa JE, Staub JE, Chung SM, Cuevas HE, McCreight JD: Detection of QTL for yield-related traits using recombinant inbred lines derived from exotic and elite US Western Shipping melon germplasm. Theor Appl Genet 2007;114; 1185-1201. | Article

27. Yuan XJ, Li XZ, Pan JS, Wang G et al: Genetic linkage map construction and location of QTL for fruit-related traits in cucumber. Plant Breed 2008;127; 180-188,. | Article

28. Tanksley SD, McCouch SR: Seed banks and molecular maps: unlocking genetic potential from the wild. Science $1997 ; 277 ;(5329.) ; 1063-$ 6. | Pubmed

29. Eduardo I, Arus P, Monforte AJ, Obando J et al. Estimating the genetic architecture of fruit quality traits in melon using a genomic library of near isogenic lines. J Amer Soc Hort Sci 2007;132; 80-89. | Article

30. Paris KM, Zalapa JE, McCreight JD, Staub JE: Genetic dissection of fruit quality components in melon (Cucumis melo L.) using a RIL population derived from exotic and elite US Western Shipping germplasm. Mol Breed 2008;22; 405-419. | Article

31. Serquen FC, Bacher J, Staub JE: Mapping and QTL analysis of a narrow cross in cucumber (Cucumis sativus $L$.) using random amplified polymorphic DNA markers. Mol Breed 1997;3; 257-268. | Article

32. Fazio G, Staub JE, Stevens MR: Genetic mapping and QTL analysis of horticultural traits in cucumber ( Cucumis sativus L.) using recombinant inbred lines. Theor App/ Genet 2003; 107;(5.);864-74. | Article $\mid \underline{\text { Pubmed }}$ 